\title{
Effect of nonuniform sintering on mechanical and thermal properties of silica-based ceramic cores
}

\author{
Zhi-ping Pan ${ }^{1,2}$, *Jian-zheng Guo ${ }^{2,3}$, Shuang-ming Li', Xu-guang Li ${ }^{1}$ \\ 1. State Key Laboratory of Solidification Processing, Northwestern Polytechnical University, Xi'an 710072, China \\ 2. Wedge Central South Research Institute, Shenzhen 518045, Guangdong, China \\ 3. Powder Metallurgy Research Institute, Central South University, Changsha 410083, China
}

\begin{abstract}
During sintering of the silica-based ceramic core of turbine blades, a phenomenon called "nonuniform sintering" occurs that negatively affects the thermal and mechanical properties of the core. Standard samples of silica-based core were prepared by an injection molding method and sintered with alumina backfilling powder with different sodium contents. The effect of sodium content on the nonuniform sintering of silica-based cores and the thermal and mechanical properties was evaluated. Results show that the sintering level and the content of $\alpha$-cristobalite in the surface layer are significantly higher than that of the sample interior. A considerable number of microcracks are found in the surface layer due to the $\beta$ to $\alpha$-phase transition of cristobalite. As the sodium content in the alumina powder decreases, the level of the nonuniform sintering and the amount of crystallized cristobalite in the surface layer decrease, which is beneficial to the thermal expansion and flexural strength at ambient temperature. The flexural strength and thermal deformation at high temperature are improved by reducing the surface cracks, but deteriorated with the decrease of the cristobalite crystallization when the surface cracks are macroscopically invisible.
\end{abstract}

Key words: silica-based ceramic core; non-uniform sintering; alkali metal content; mechanical and thermal properties

CLC numbers: TG221 ${ }^{+} .1 \quad$ Document code: $\mathrm{A}$

Article ID: 1672-6421/2021 05-457-06

\section{Introduction}

Single crystal gas turbine blades and vanes, which have complex hollow structures, are one of the most important parts in gas turbine engines. The single crystal microstructure can efficiently enhance the heat bearing capacity of turbine blades so as to improve engine performance ${ }^{[1]}$. The most efficient technology for manufacturing single crystal turbine blades is the investment casting process based on Bridgman's directional solidification theory. This technology uses complex ceramic cores fabricated by injection molding to form the internal cooling passages in the hollow gas turbine blade ${ }^{[2,3]}$. A silica-based ceramic core is typically used in the manufacture of single crystal hollow turbine blades due to its superior low thermal expansion coefficient $\left(0.55 \times 10^{-6} \mathrm{~K}^{-1}\right.$ between $25^{\circ} \mathrm{C}$ and $\left.1,000{ }^{\circ} \mathrm{C}\right)$, excellent chemical stability with molten metals, and

\footnotetext{
*Jian-zheng Guo
}

Born in 1967, Ph. D, Professor. His research interests mainly focus on numerical simulation, nickel-based superalloy design, powder metallurgy and ceramic core technology development.

E-mail: guo_jianzheng@qq.com

Received: 2021-01-26; Accepted: 2021-05-12 good leachability ${ }^{[4-8]}$.

It is critical to control the crystallization of cristobalite for silica-based cores to achieve a good overall performance ${ }^{[9]}$. Devitrification of amorphous fused silica to cristobalite weakens the sintered silica because the volume contraction caused by cristobalite $\beta$ to $\alpha$ phase transformation during the cooling stage induces microcracks ${ }^{[10,11]}$. In addition, cristobalite has a higher strength and better thermodynamic structural stability compared with amorphous silica, and can disturb the viscous flow of amorphous materials, hence, the crystallization of fused silica to cristobalite can enhance the flexural strength and reduce the thermal deformation ${ }^{[12,13]}$. The cristobalite crystallization of silica-based ceramics can be controlled with additives ${ }^{[14]}$. Many additives, such as alumina ${ }^{[15]}$, cristobalite seed ${ }^{[16]}$, zircon ${ }^{[17,18]}$, silicon carbide ${ }^{[13]}$, and silica nano-powders ${ }^{[19]}$, have been used as crystal nuclei of cristobalite to improve the flexural strength and the creep behavior of silicabased ceramic cores.

In addition, alkali metal impurities, especially sodium $(\mathrm{Na})$, in the industrial alumina backfilling powders can diffuse into the surface of the silicabased core and promote cristobalite crystallization and sintering level of the surface ${ }^{[20-22]}$. This nonuniform 
sintering ${ }^{[23]}$ causes differences in the degree of sintering from the surface to the interior of the ceramic core. In fact, nonuniform sintering is common in the production of silicabased cores. In practice, engineers generally control the level of nonuniform sintering by empirically observing the surface crack state of the silica-based core. There is no clear understanding on the mechanism and the degree of influence of nonuniform sintering on core performance.

In this work, the standard samples with different nonuniform sintering levels were prepared using injection molding method and sintered using alumina powder with different $\mathrm{Na}$ contents after purification treatment. The effects of $\mathrm{Na}$ content on nonuniform sintering, as well as its influence on the thermal expansion, flexural strength and thermal deformation of silicabased core were studied.

\section{Materials and experimental procedure}

Fused silica powders with an average particle size of $16.6 \mu \mathrm{m}$ were used as the main compounds which contributed $82 \%$ of the weight of the refractory powder. Zircon powders with an average particle size of $5.93 \mu \mathrm{m}$ were used as the mineralizer. Table 1 lists the main compounds of the raw materials used in this study. The weight ratio of thermoplastic binders to refractory powder was $18 \%$. The compounds and powder size distribution were measured with an X-ray fluorescence spectrometer and a laser particle size analyzer, respectively.

The green samples were injection-molded using a C-frame ceramic injection machine (SA56-25-24, MPI Incorporated,

Table 1: Main compounds of raw materials used in experiments

\begin{tabular}{cccccc}
\multicolumn{2}{c}{ Fused silica } & \multicolumn{2}{c}{ Zircon } & \multicolumn{2}{c}{ Alumina } \\
\hline Composition & wt. \% & Composition & wt. $\%$ & Composition & wt. \% \\
$\mathrm{SiO}_{2}$ & 99.62 & $\mathrm{ZrO}_{2}$ & 65.99 & $\mathrm{Al}_{2} \mathrm{O}_{3}$ & 99.64 \\
$\mathrm{Al}_{2} \mathrm{O}_{3}$ & 0.12 & $\mathrm{SiO}_{2}$ & 32.34 & $\mathrm{SiO}_{2}$ & 0.12 \\
$\mathrm{Fe}_{2} \mathrm{O}_{3}$ & 0.01 & $\mathrm{Al}_{2} \mathrm{O}_{3}$ & $\mathrm{Bal}$ & $\mathrm{Fe}_{2} \mathrm{O}_{3}$ & 0.02 \\
$\mathrm{~K}_{2} \mathrm{O}$ & 0.02 & & & & \\
$\mathrm{Na}_{2} \mathrm{O}$ & 0.01 & & & & \\
\end{tabular}

United States), and sintered at $1,200{ }^{\circ} \mathrm{C}$ for $6 \mathrm{~h}$ in a chamber furnace (N450 DB200, Nabertherm Industrial Furnaces Co., Ltd., Federal Republic of Germany). To provide good support and prevent deformations or cracks in the samples during sintering, industrial alumina powders with a purity of $99.64 \mathrm{wt} . \%$ and an average particle size of $59.7 \mu \mathrm{m}$ were used. The contents of alkali metal in alumina powder used for sintering Samples \#0-\#5 were measured using an inductively coupled plasma mass spectrometer (ICP-MS, NexIONTM 350D, PerkinElmer USA), and are listed in Table 2.

To observe macro-cracks on the sample surface, a solution of methylene blue in alcohol was applied to the sample surface.

Table 2: Contents of alkali metal in alumina powder used for sintering samples

\begin{tabular}{cccccc}
$\begin{array}{c}\text { Sample } \\
\text { No. }\end{array}$ & \multicolumn{5}{c}{ Alkali metal content $\left(\mu \mathrm{g} \cdot \mathrm{mL}^{-1}\right)$} \\
\hline$\# 0$ & $\mathrm{Na}$ & $\mathrm{K}$ & $\mathrm{Li}$ & $\mathrm{Ca}$ & $\mathrm{T}$ \\
\hline$\# 1$ & 17.43 & 1.47 & 1.26 & 2.26 & 22.42 \\
$\# 2$ & 10.25 & 1.32 & 1.20 & 2.17 & 14.94 \\
$\# 3$ & 9.68 & 1.30 & 1.12 & 1.99 & 14.09 \\
$\# 4$ & 8.47 & 1.28 & 1.13 & 1.73 & 12.61 \\
$\# 5$ & 8.11 & 1.22 & 1.26 & 1.72 & 12.31
\end{tabular}

The solution can penetrate into the cracks and reveal the crack network. This method was suitable for samples with a certain depth of cracks, but it was difficult to distinguish superfine and shallow cracks. The macro and microscopic fractured surface morphologies of the samples were observed with a stereomicroscope (SMZ1270, Nikon, Japan) and a scanning electron microscope (SEM, sigma300, Zeiss, Germany), respectively. The amount of crystalline phase in the sintered samples was determined by an X-ray powder diffractometer (Rigaku D/Max2500pc, Japan) with Ni-filtered CuK $\alpha$ radiation, with a step size of $0.02^{\circ}$ and detecting time of $1 \mathrm{~s}$ at each step. The thermal expansion of the sintered sample from ambient temperature to $1,500{ }^{\circ} \mathrm{C}$ was determined by a thermal dilatometer (DIL402 Expedis Classic, Netzsch, Germany) with a heating rate of $3 \mathrm{~K} \cdot \mathrm{min}^{-1}$ and a push load of $200 \mathrm{mN}$. The standard sample had a diameter of $6 \mathrm{~mm}$ and a length of $25 \mathrm{~mm}$.

Flexural strength at ambient temperature and $1,500{ }^{\circ} \mathrm{C}$ was measured with a 3-point bending fixture in a universal testing machine (HSST16-3000LX/W, Sinosteel Luoyang Institute of Refractories Research Co., Ltd., China) with a cross head speed of $6 \mathrm{~mm} \cdot \mathrm{min}^{-1}$ and span of $30 \mathrm{~mm}$. To test the flexural strength at $1,500{ }^{\circ} \mathrm{C}$, the sample was heated to $1,500{ }^{\circ} \mathrm{C}$ at $10^{\circ} \mathrm{C} \cdot \mathrm{min}^{-1}$ rate and held for $30 \mathrm{~min}$ before loading. Thermal deformation at $1,500{ }^{\circ} \mathrm{C}$ was measured by a single-fulcrum method. The bar samples were held at $1,500{ }^{\circ} \mathrm{C}$ for $30 \mathrm{~min}$. The pendulous height was measured as the deformation value after the samples cooled down to room temperature. The reported flexural strength 
and thermal deformation results were an average of five tests. The dimensions of the test bars used for flexural strength and thermal deformation testing were $60 \mathrm{~mm} \times 10 \mathrm{~mm} \times 4 \mathrm{~mm}$ and $120 \mathrm{~mm} \times 10 \mathrm{~mm} \times 4 \mathrm{~mm}$, respectively.

\section{Results and discussion}

\subsection{Morphology of external and fractured surfaces}

Figure 1 shows a great number of grid-like cracks evenly distributed on the surface of Samples \#0-\#3. The size of the crack grids is $0.3-0.5 \mathrm{~mm}$. On the surface of Sample \#4, only a small number of cracks on the edges are observed. No cracks are found for Sample \#5. Figure 2 shows the macroscopic morphologies of the fractured surfaces. The structures in the surface layer are significantly different from those in the interior of all sintered samples, which indicates differences in phase constitution and sintering level.

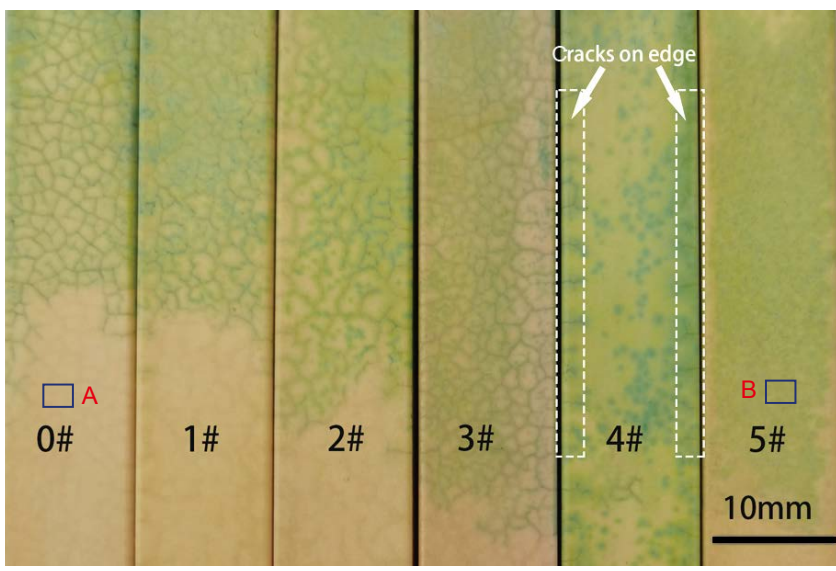

Fig. 1: Macroscopic external morphologies of Samples \#0 to \#5
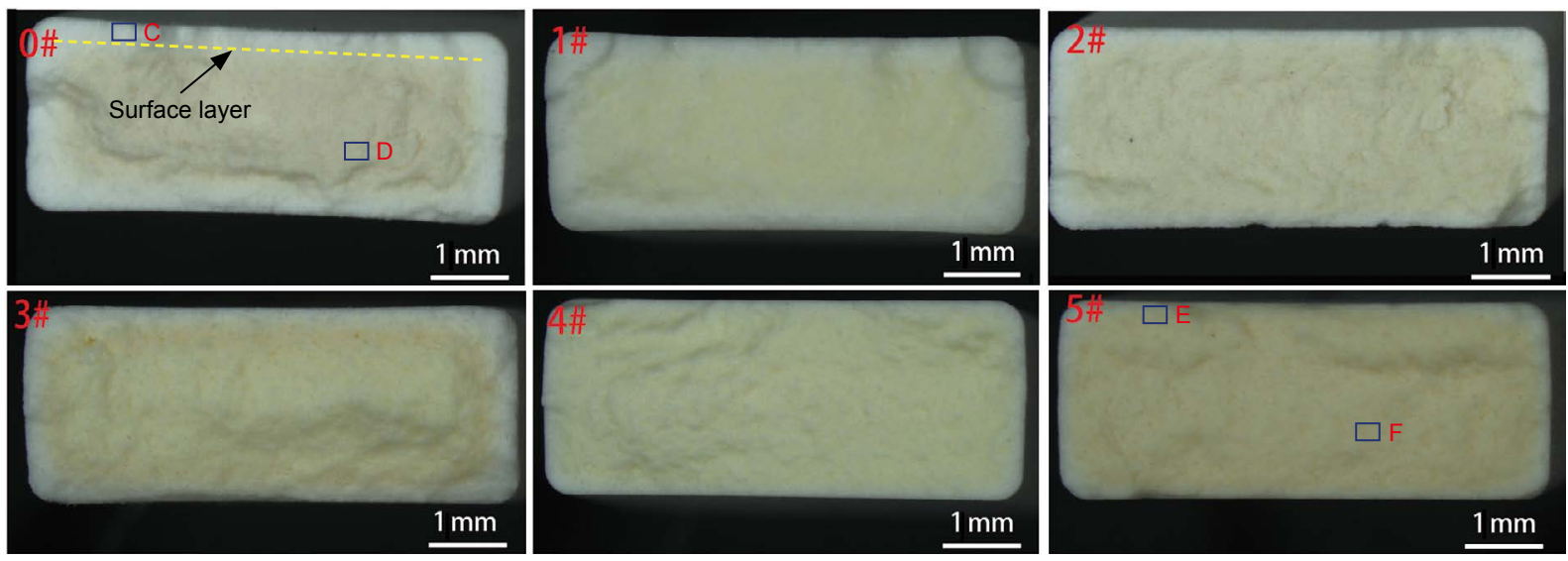

Fig. 2: Macroscopic fractured surface morphologies of Samples \#0 to \#5

Figure 3 shows the microscopic morphologies of Samples $\# 0$ and \#5 at different positions. Figures 3(a) to (f) are corresponding to the microstructures in Areas A to F in Figs. 1 and 2, respectively. Many micro-cracks are found on the surface [Fig. 3(a)] and the fracture surface [Fig. 3(b)] of Sample \#0; no micro-cracks in the central area [Fig. 3(c)] are observed. For Sample \#5, although no macroscopically visible crack is found on the surface, microcracks still appear on the large quartz glass surface [Fig. 3(d)]. However, microcracks are smaller and fewer in number than the cracks on the surface of Sample \#0; no crack is found either on the edge of the fracture surface [Fig. 3(e)] or central area [Fig. 3(f)] of the Sample \#5. Furthermore, as shown in Fig. 3, the fine quartz glass particles in the fracture surface edge are more rounded, and the pores are finer than those of the central area of both Samples \#0 and $\# 5$. This difference in structure indicates that the sintering level of the surface layer is higher than that of the interior. Because the green bodies of the samples was backfilled by alumina powders during sintering, the alkali metal impurities, especially the elemental $\mathrm{Na}$ in the industrial alumina powders, diffuses into the sample surface layers. $\mathrm{Na}$ forms a low-melting eutectic with $\mathrm{SiO}_{2}$ at high temperature (approximately $780{ }^{\circ} \mathrm{C}$ ), which reduces the viscosity of quartz glass and promotes the sintering ${ }^{[24]}$. Hence, the sintering level of the surface layer is higher than that of the interior.

It is well known that alkali metal ions, especially $\mathrm{Na}$ ions ${ }^{[20-22]}$, promote the cristobalite crystallization. $\mathrm{Na}$ in the industrial alumina powders diffuses into the sample surface layers during the sintering process, causing a significantly higher cristobalite fraction in the surface layer compared with the interior. Table 3 lists the phase constitution of the surface layer (Area A in Fig. 4) and interior (Area B in Fig. 4) and the nominal constitution of Sample \#0. The sample is consisted of $\alpha$-cristobalite, amorphous silica, and $\mathrm{ZrSiO}_{4}$. The cristobalite phase in the surface layer is as high as $39.0 \%$, but it is not detected in the interior.

Based on the microscopic morphologies of the surface layer [Fig. 3(b, e)] and the phase constitution results (Table 3), the sintering level and the cristobalite content of the surface layer are higher than that of the interior. The differences of sintering level and cristobalite content between the surface layer and the interior result in a different color in the macroscopic fracture morphology of the sample. As shown in Fig. 2, the macroscopic morphologies of the surface layer are white, while those of the sample interior are dark yellow. Therefore, the thickness of the surface layer was used to reflect the 

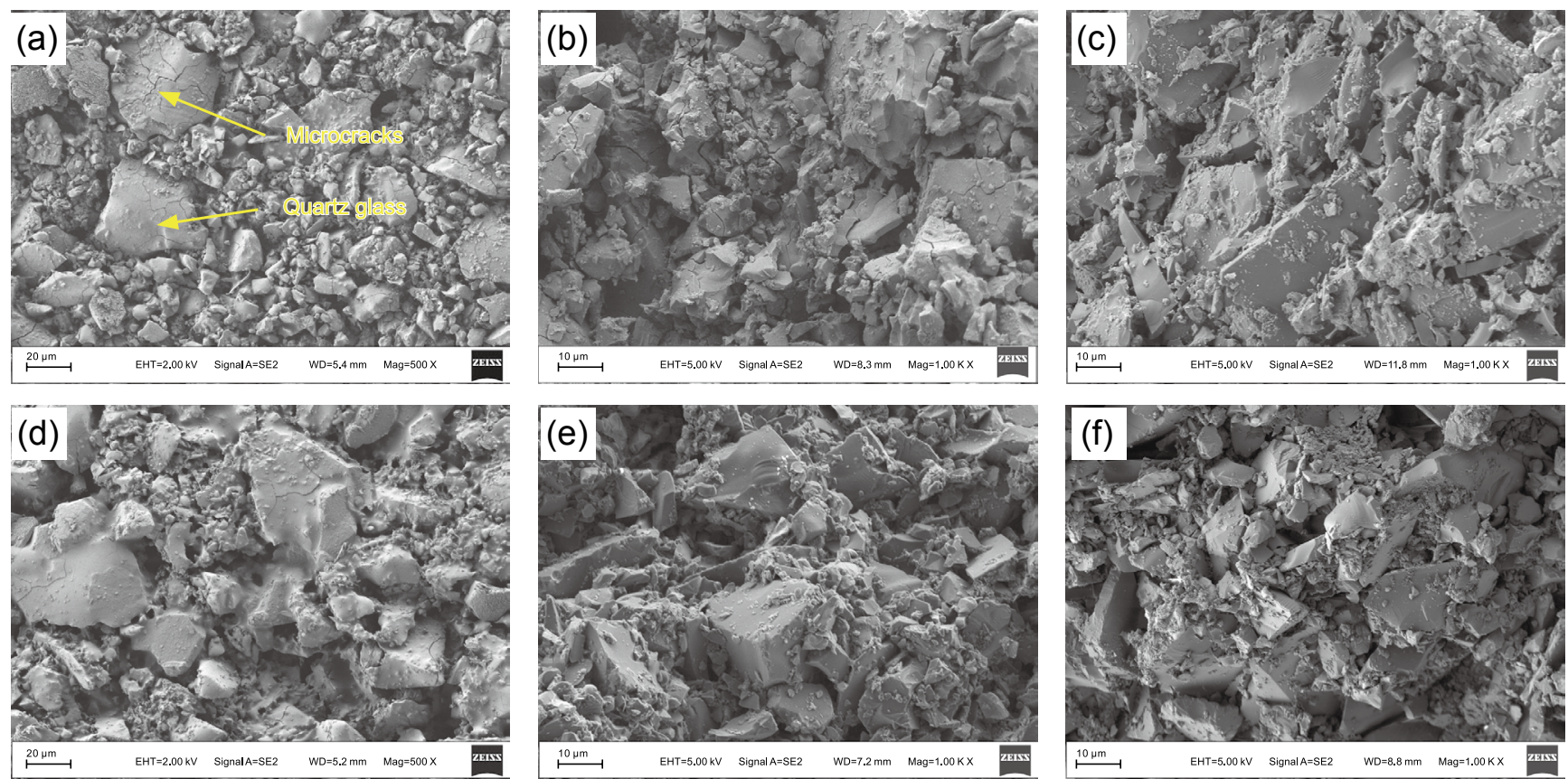

Fig. 3: Microscopic morphologies of Sample \#0 and \#5 at different positions (Areas $A$ to $F$ in Figs. 1 and 2): (a), (d) surfaces of Samples \#0 (Area A) and \#5 (Area B); (b), (c) fracture surface edge (Area C) and central area (Area D) of Sample \#0; (e), (f) fracture surface edge (Area E) and central area (Area F) of Sample \#5

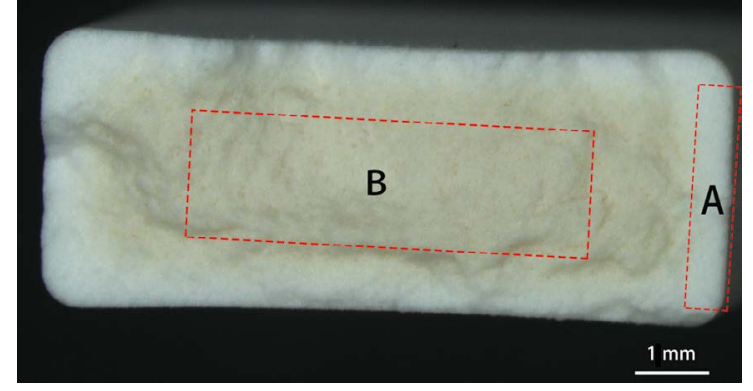

Fig. 4: X-ray diffraction sampling location of Sample \#0

Table 3: Phase constitution of Sample \#0 (wt.\%)

\begin{tabular}{cccc} 
Area & a-cristobalite & $\mathrm{ZrSiO}_{4}$ & Others \\
Nominal & 16.1 & 12.0 & 72.0 \\
A (surface layer) & 39.0 & 10.1 & 51.0 \\
B (interior) & 0 & 14.1 & 85.9 \\
\hline
\end{tabular}

level of the nonuniform sintering and the cristobalite content of the samples. The thicker the surface layer, the higher the nonuniform sintering level and cristobalite content. Considering that the $\mathrm{Na}$ content of the alumina backfilling powder used to sinter the Samples \#0 to \#5 gradually decreases, the thickness of the surface layer of the Samples \#0 to \#5 gradually decreases accordingly, as shown in Fig. 5. This confirms that, as the Na content in the alumina powder decreases, the degree of the nonuniform sintering and the cristobalite content gradually decrease.

During the cooling stage of sintering between $250-270{ }^{\circ} \mathrm{C}$, the high-temperature cristobalite ( $\beta$-cristobalite) on the surface of the quartz glass transforms into low-temperature opaque

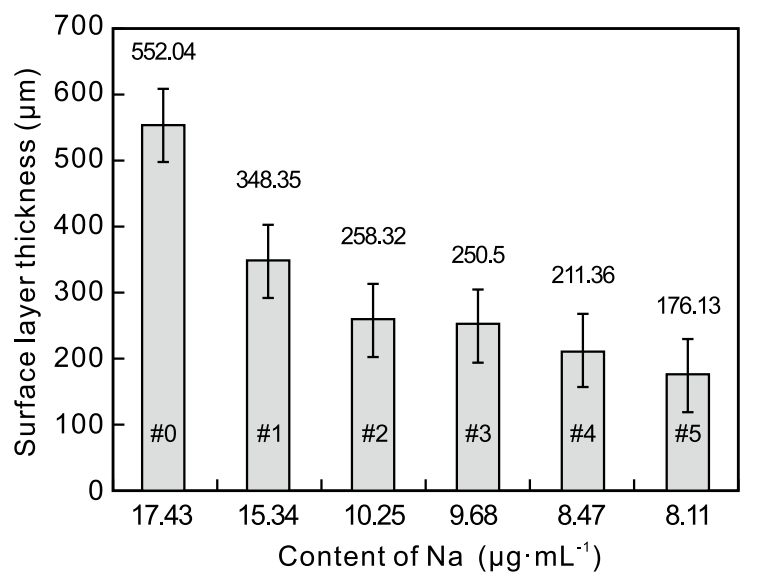

Fig. 5: Surface layer thickness of samples sintered with alumina powders with various $\mathrm{Na}$ contents

cristobalite ( $\alpha$-cristobalite). There is about a $5 \%$ volume contraction during this phase transformation, which causes microcrack formation on the surface of the quartz glass ${ }^{[25]}$. Sample \#0 was sintered with the highest content of Na. The crystallization of cristobalite phase in the surface layer was more successful during the sintering, and caused the most serious cracks on the sample surface due to the volume contraction. With the decrease of $\mathrm{Na}$ content in the alumina powder, the surface cracks gradually reduce. Sample \#5 has only micro-cracks on a thinner surface layer, and it is almost impossible to distinguish the cracks macroscopically. In addition, the crystallization of cristobalite can prevent further sintering of quartz glass through obstructing the viscous flow of quartz glass. That is why there is an interface between the surface layer and interior of the samples which have different sintering levels. 


\subsection{Effect of nonuniform sintering on thermal and mechanical performance}

Figure 6 shows the thermal expansion curves for Samples $\# 0$, \#3, and \#5. There are three transition points in the linear expansion curves (Points A, B, and C in Fig. 6). At the transition Point A (approximately 200-210 ${ }^{\circ} \mathrm{C}$ ), the low-temperature cristobalite transforms to the hightemperature cristobalite phase, accompanied by a volume increase of $2.8 \%{ }^{[19]}$. The higher the cristobalite content in the sample, the greater the expansion is at transition Point A. When the samples are heated to transition Point B (approximately $1,100-1,160{ }^{\circ} \mathrm{C}$ ), sintering densification dominated by viscous flow occurs, resulting in contraction of the specimens. This contraction slows down the thermal expansion of the specimens or even turns into contraction in some cases. The greater the amount of cristobalite crystallized in a sample, the less the amount of fused viscous flow quartz glass. In addition, the cristobalite phase reduces the viscous flow of the quartz glass. As a result, Sample \#0 has the smallest contraction caused by viscous flow, and the thermal expansion curve in section BC is almost flat because of its higher cristobalite content. Conversely, Sample \#3 shows a slight contraction in section $\mathrm{BC}$, and Sample \#5 has the greatest contraction. After being heated to Point $\mathrm{C}$ (approximately $1,210-1,300{ }^{\circ} \mathrm{C}$ ), a large amount of cristobalite begins to crystallize. The fused quartz gradually transforms into cristobalite, and the expansion of the sample gradually exceeds the contraction.

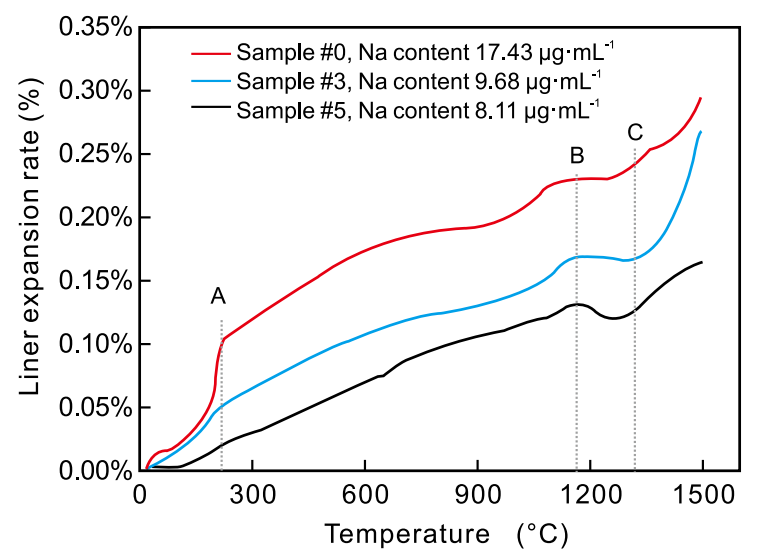

Fig. 6: Thermal expansion of samples sintered with alumina powder with various $\mathrm{Na}$ contents

Figure 7 shows the flexural strength and the thermal deformation of samples sintered by alumina powders with different $\mathrm{Na}$ contents. The flexural strength of the sample at ambient temperature is improved from 9.36 $\mathrm{MPa}$ to $16.90 \mathrm{MPa}$ as the $\mathrm{Na}$ content decreases from $17.43 \mu \mathrm{g} \cdot \mathrm{mL}^{-1}$ (Sample \#0) to $8.11 \mu \mathrm{g} \cdot \mathrm{mL}^{-1}$ (Sample \#5). In the three-point bending test, surface cracks become weak points of fracture due to stress concentration ${ }^{[26]}$. As mentioned above, as the Na content in the alumina backfilling powder decreases, the cracks in the surface layer caused by cristobalite $\beta$ to $\alpha$-phase transformation are reduced. Hence, the flexural strength at ambient temperature is

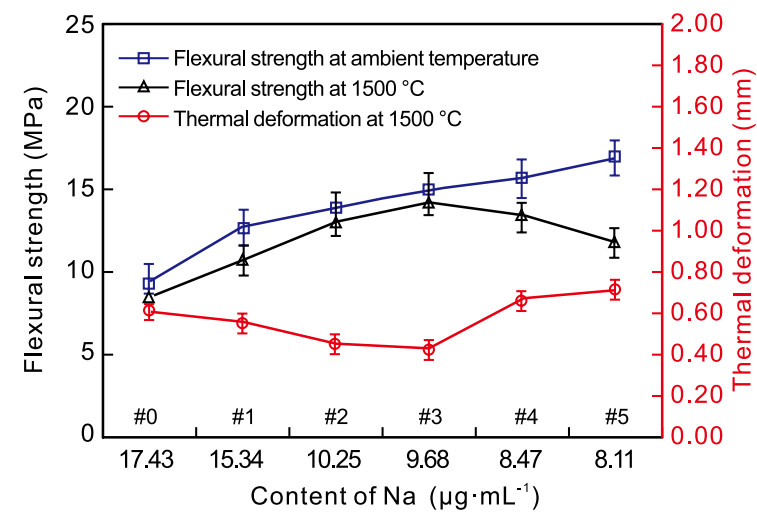

Fig. 7: Flexural strength and thermal deformation of samples sintered with alumina powder with various $\mathrm{Na}$ contents

improved accordingly. The reduction of cracks also contributes to the improvement of high temperature flexural strength. This trend was demonstrated by $1,500{ }^{\circ} \mathrm{C}$ flexural strength results of Samples \#0-\#3. In fact, the high temperature flexural strength of the silica-based ceramic core is determined by the surface cracks and the amount of cristobalite crystallization. The cristobalite phase, due to its higher strength compared with that of quartz glass and its enhancing effect to the crystallization of cristobalite, is beneficial to improve the high temperature flexural strength of the silica-based cores ${ }^{[11,12]}$. Therefore, as the $\mathrm{Na}$ content decreases, the surface cracks decrease rapidly, and the high temperature flexural strength of the sample is significantly improved. However, as the Na content continues to decrease, the surface cracks of the sample reduce to a certain level (in this study, when the cracks are macroscopically invisible), and the improvement effect on the high temperature flexural strength becomes very limited, while the amount of cristobalite crystallization of the sample continues to decrease, resulting in a decrease in the high temperature flexural strength of the sample. This trend was verified by the flexural strength at $1,500{ }^{\circ} \mathrm{C}$ of Samples \#3-\#5.

The thermal deformation of the Samples $\# 0$ to $\# 5$ at $1,500{ }^{\circ} \mathrm{C}$ (Fig. 7) firstly decreases and then increases as the Na content in the alumina powder decreases. Because the thermal deformation was measured with the single fulcrum method, the cracks at the fulcrum position exacerbated the deformation of the test bar. The gradual decrease in the thermal deformation of Samples \#0 to \#3 reflects this trend. The thermal deformation was due to the creep behavior of quartz glass caused by viscous flow at high temperature ${ }^{[27]}$, whereas the cristobalite phase had a thermodynamically stable crystal structure below $1,750{ }^{\circ} \mathrm{C}$ that was difficult to flow ${ }^{[28]}$. Therefore, if the quartz glass is transformed into a cristobalite crystal at a lower temperature, the thermal deformation will be smaller. The sample itself has a higher content of cristobalite, which is not only conducive to the reduction of thermal deformation, but also promotes the crystallization of cristobalite and further reduces thermal deformation. As the cristobalite content of Samples \#3 to \#5 decreases successively, although the surface cracks have been reduced to be invisible macroscopically, the thermal deformation of Samples \#3 to \#5 gradually increases. 


\section{Conclusion}

By controlling the Na content in the alumina backfilling powder, silica-based cores with different levels of nonuniform sintering were prepared. The alumina backfilling powder containing $\mathrm{Na}$ contributes to a significantly higher degree of the cristobalite crystallization and sintering level in the surface layer compared with the interior. During cooling, a great number of cracks form in the surface layer due to the cristobalite $\beta$ to $\alpha$-phase transformation. Otherwise, with a decrease in $\mathrm{Na}$ content in the alumina powder, both the level of nonuniform sintering and the amount of crystallized cristobalite in the surface layer are diminished, and the surface cracks become shallow and fewer in number.

The nonuniform sintering of silica-based cores has important effects on the mechanical and thermal properties of silica-based cores. As the nonuniform sintering level weakens, the thermal expansion decreases, and the flexural strength at ambient temperature is improved. However, the high-temperature flexural strength and thermal deformation are affected by the severity of the surface cracks and the amount of crystallized cristobalite. The reduction in the degree of nonuniform sintering reduces the cracks in the surface layer, which enhances the high-temperature flexural strength and reduces the thermal deformation. When the surface cracks are macroscopically invisible, the high-temperature flexural strength and thermal deformation are controlled by the crystallization of cristobalite, and worsen with the reduction of cristobalite amount.

\section{Acknowledgements}

This work was funded by the Shenzhen Development and Reform Commission Project (SZDRC 20181000). This research was also made possible through funding from the Wedge Central South Research Institute, China, and supported by the State Key Laboratory of Solidification Processing, Northwestern Polytechnical University, China.

\section{References}

[1] Zhang $H, X u Q Y$, Liu B C. Numerical simulation and optimization of directional solidification process of single crystal superalloy casting. Materials, 2014(3), 7: 1625-1639.

[2] Kim E H, Park H Y, Lee C L, et al. Single crystal casting of gas turbine blades using superior ceramic core. J. Mater. Res. Technol., 2020, 9(3): 3348-3356.

[3] Pattnaik S, Karunakar D B, Jha P K. Developments in investment casting process-A review. J. Mater. Process. Technol., 2012, 212(11): 2332-2348.

[4] Wereszczak A A, Breder K, Ferber M K, et al. Dimensional changes and creep of silica core ceramics used in investment casting of superalloys. J. Mater. Sci., 2002, 37(19): 4235-4245.

[5] Huseby I C, Borom M, Greskovich C D. High temperature characterization of silica-base cores for superalloys. Am. Ceram. Soc. Bull., 1979, 58(4): 448-452.

[6] Chao C H, Lu H Y. Optimal composition of zircon-fused silica ceramic cores for casting superalloys. J. Am. Ceram. Soc., 2002, 85(4): 773-779.

[7] Kim E H, Cho G H, Yoo Y S, et al. Development of a new process in high functioning ceramic core without shape deformation. Ceram. Int., 2013, 39(8): 9041-9045.
[8] Kim Y H, Yeo J G, Choi S C. Shrinkage and flexural strength improvement of silica-based composites for ceramic cores by colloidal alumina infiltration. Ceram. Int., 2016, 42(7): 8878-8883.

[9] Breneman R C, Halloran J W. Effect of cristobalite on the strength of sintered fused silica above and below the cristobalite transformation. J. Am. Ceram. Soc., 2015, 98(5): 1611-1617.

[10] Kazemi A, Faghihi-Sani M A, Alizadeh H R. Investigation on cristobalite crystallization in silica-based ceramic cores for investment casting. J. Eur. Ceram. Soc., 2013, 33(15-16): 3397-3402.

[11] Chao $\mathrm{C} \mathrm{H}$, Lu H Y. Stress-induced $\beta \rightarrow \alpha$-cristobalite phase transformation in $\left(\mathrm{Na}_{2} \mathrm{O}+\mathrm{Al}_{2} \mathrm{O}_{3}\right)$-codoped silica. Mater. Sci. Eng. A: Struct., 2002, 328(1-2): 267-276.

[12] Zhong J W, Xu Q Y. High-temperature mechanical behaviors of $\mathrm{SiO}_{2}$-based ceramic core for directional solidification of turbine blades. Materials, 2020, 13(20): 4579-4590.

[13] Kim Y H, Yeo J G, Lee J S, et al. Influence of silicon carbide as a mineralizer on mechanical and thermal properties of silicabased ceramic cores. Ceram. Int., 2016, 42(13):14738-14742.

[14] Chen X, Liu C Y, Zheng W L, et al. High strength silica-based ceramics material for investment casting applications: Effects of adding nanosized alumina coatings. Ceram. Int., 2020, 46(1): 196-203.

[15] Liang J J, Lin Q H, Zhang X, et al. Effects of alumina on cristobalite crystallization and properties of silica-based ceramic cores. J. Mater. Sci. Technol., 2017, 33(2): 204-209.

[16] Wang L Y, Hon M H. The effect of cristobalite seed on the crystallization of fused silica based ceramic core: A kinetic study. Ceram. Int., 1995, 21(3): 187-193.

[17] Wilson P J, Blackburn S, Greenwood R W, et al. The role of zircon particle size distribution, surface area and contamination on the properties of silica-zircon ceramic materials. J. Eur. Ceram. Soc., 2011, 31(9): 1849-1855.

[18] Kazemi A, Faghihi-Sani M A, Nayyeri M J, et al. Effect of zircon content on chemical and mechanical behavior of silica-based ceramic cores. Ceram. Int., 2014, 40(1): 1093-1098.

[19] Xu X Q, Niu S X, Wang X G, et al. Fabrication and casting simulation of composite ceramic cores with silica nanopowders. Ceram. Int., 2019, 45(15): 19283-19288.

[20] Pascova R, Avdeev G, Gutzow I, et al. Refractory alkalifree cristobalite glass-ceramics: Activated reaction sintercrystallization synthesis and properties. Int. J. Appl. Glass Sci., 2012, 3(1): 75-87.

[21] Silica V, Wagstaff F E, Richards K J. Preparation and crystallization behavior of oxygen-deficient vitreous silica. J. Am. Ceram. Soc., 1965, 48(7): 382-383.

[22] Bihuniak P P. Effect of trace impurities on devitrification of vitreous silica. J. Am. Ceram. Soc., 1983, 66(10): 188-189.

[23] Taylor D, Penny A N, Robinson A M. Non-uniform sintering and devitrification in fused silica. Proceedings of the British Ceramic Society, 1973, 22: 55-66.

[24] Hetherington G, Jack K H, Kennedy J C. The viscosity of vitreous silica. Phys. Chem. Glasses, 1964, 5: 130-136.

[25] Leadbetter A J, Wright A F. The $\alpha-\beta$ transition in the cristobalite phases of $\mathrm{SiO}_{2}$ and $\mathrm{AIPO}_{4}$ I. X-ray studies. Philos. Mag., 1976, 33(1): 105-112.

[26] Dai Y J, Yin Y C, Xu X F, et al. Effect of the phase transformation on fracture behavior of fused silica refractories. J. Eur. Ceram. Soc., 2018, 38(16): 5601-5609.

[27] Sacks M D, Bozkurt N, Scheiffele G W. Fabrication of mullite and mullite-matrix composites by transient viscous sintering of composite powders. J. Am. Ceram. Soc., 1991, 74(10): 24282437.

[28] Swainson I P, Dove M T. On the thermal expansion of $\beta$-cristobalite. Phys. Chem. Miner., 1995, 22(1): 61-65. 